\section{Deborah Doniach, a pioneer in the field of autoimmunity}

Deborah Doniach (1912-2004) was a clinician and immunologist who made the ground-breaking observation of the autoimmune basis of Hashimoto disease, which damages the thyroid gland. This paved the way for the subsequent identification of other organ-specific autoimmune diseases.

Deborah was born in Geneva, studied medicine at the Sorbonne in Paris and completed her medical degree at the Royal Free Hospital Medical School in London. After graduation, she worked as a research assistant at the Royal Free Hospital and then as an assistant lecturer in chemical pathology at the Middlesex Hospital, London. This was followed by an endocrinology post at the Middlesex Hospital and afterwards a position, initially as Honorary Consultant Immunopathologist and subsequently as Professor of Clinical Immunology, in the new Department of Immunology at the Middlesex Hospital.

Whilst diagnosing and treating patients with thyroid disease, she noted that following thyroid resection the previously elevated plasma immunoglobulin levels seen in Hashimoto disease fell to normal levels. Deborah was aware that patients with Hashimoto disease had plasma cell infiltration of their thyroid glands and she made the conceptual leap that these cells were recognizing thyroid antigens. Together with Ivan Roitt and Peter Campbell, she tested the hypothesis that plasma cells in the patients produced immunoglobulins that recognized thyroid antigens. They demonstrated that sera from the patients contained antibodies against thyroid antigens, indicating an autoimmune basis for Hashimoto disease. Deborah retained a fruitful collaboration with Ivan Roitt, and the Department of Immunology at the Middlesex Hospital became an internationally renowned centre for the study of autoimmune disease.
As a clinician, Deborah recognized the need for a clinical diagnostic service to monitor patient autoantibodies and pushed for the establishment of a clinical immunology service in the Department of Immunology at the Middlesex Hospital. As well as forming a blueprint for the diagnostic and monitoring facilities now routinely available, this service also greatly assisted the development of many clinical research programmes. The Department of Immunology at the Middlesex Hospital was a vibrant research community not least because of Deborah's enthusiasm for new ideas and thirst for knowledge.

In addition to her longstanding collaboration with Ivan Roitt, Deborah established very productive collaborations with many scientists and clinicians, including Dame Sheila Sherlock, Noel Ling, Gianfranco Bottazzo, Hemmo Drexhage, Ricardo Pujol-Borrell and Rita Mirakian. She and her colleagues identified the thyroid antigens recognized by the immune system in Hashimoto disease, established a role for antimitochondrial autoantibodies in

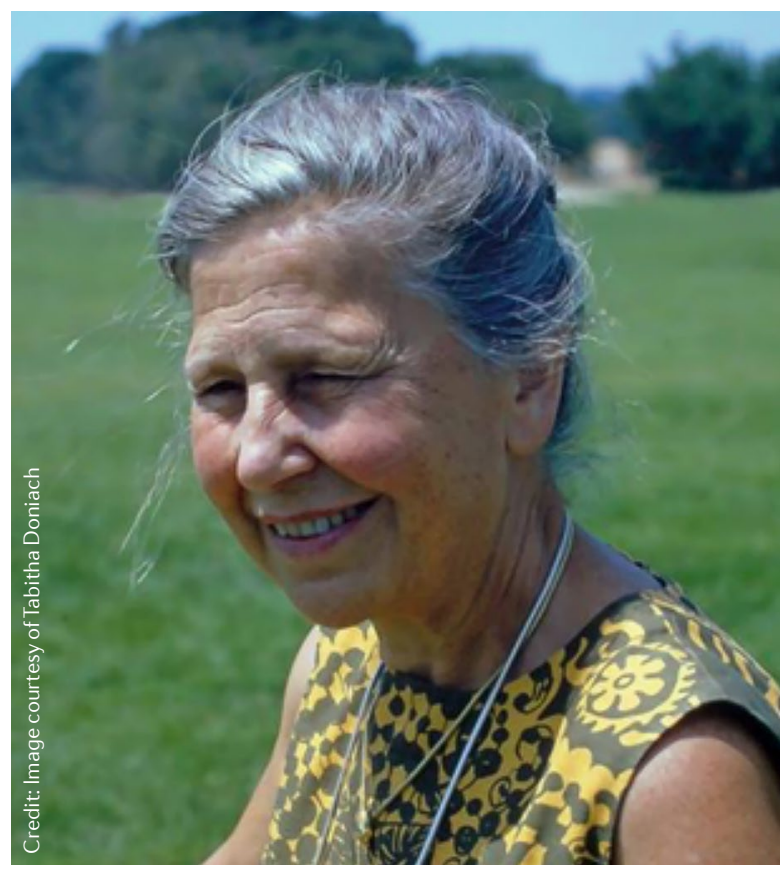

primary biliary cirrhosis and clarified how autoantibodies to gastric parietal cells play a role in pernicious anaemia. Deborah's research team were also among the first to show that autoantibodies specific for pancreatic islet cell antigens were present in the sera of patients with type 1 diabetes mellitus. Although the formal proof that type 1 diabetes mellitus was an autoimmune disease was to come later, these early studies provided an indication that there might be an autoimmune aetiology.

Deborah had a wonderfully inquisitive mind that embraced new ideas and technologies. This stood her in good stead throughout her academic career. Deborah was a remarkable woman who was undaunted by adversity and had a great love of science. Her enthusiasm was infectious and her interest in people coupled with her warm, generous nature enabled those young clinician scientists working with her to achieve their potential. The fact that she spoke several languages fluently, that she had wide-ranging interests and that she was immensely hospitable ensured that any new arrival to the Department of Immunology was rapidly put at ease.

Deborah received many awards in recognition of her studies in autoimmunity, including the Van Meter Award of the American Goitre Association, jointly with Ivan Roitt (1957), the Canada Gairdner International Award, jointly with Ivan Roitt (1964), the Prize of the British Postgraduate Federation (1967), and she was elected 'Woman Scientist of the Year' in 1984 by the Association of American Women Scientists.

Anne Cooke

\section{The author declares no competing interests.}

ORIGINAL ARTICLES Roitt, I. M. et al. Autoantibodies in Hashimoto's disease (lymphadenoid goitre). Lancet 271, 820-821 (1956) | Berg, P. A., Doniach, D. \& Roitt, I. M. Mitochondrial antibodies in primary biliary cirrhosis. I. Localization of the antigen to mitochondrial membranes.J. Exp. Med. 126, 277-290 (1967) |Bottazzo, G. F., Florin-Christensen, A. \& Doniach, D. Islet-cell antibodies in diabetes mellitus with autoimmune polyendocrine deficiencies. Lancet 304, 1279-1283 (1974)| Mirakian, R. et al. Autoimmunity to anterior pituitary cells and the pathogenesis of insulindependent diabetes mellitus. Lancet 319, 755-759 (1982)|Berg, P. A. et al. Clinical significance of mitochondrial antibodies in relation to liver disease. Lancet 318, 804 (1981) 